\title{
Colonialidade da Paz: Esforços ameaçados pelo eurocentrismo em um estudo da educação como ferramenta de paz
}

\author{
Nycolas Candido da Silva Lau ${ }^{1}$
}

\section{Resumo}

Este trabalho desenvolve uma nova definição para tratar dos entraves entre os níveis global e local nas intervenções de Organizações Internacionais nos conflitos atuais. Tal definição constrói um conceito próprio, denominado "colonialidade da paz": processo pelo qual o eurocentrismo prejudica o resultado dos esforços globais de pacificação. É um conceito que, através da "necropolítica" de Achille Mbembe, busca estender as compreensões de Aníbal Quijano sobre o eurocentrismo para o modo como as agências internacionais lidam com os conflitos armados contemporâneos. Com foco nas Nações Unidas, nosso objetivo é analisar os esforços para resolução de conflitos no mundo atual, especialmente no marco das "novas guerras", a fim de entender quais fatores estruturais fazem com que estas medidas não atinjam totalmente suas metas. Nossa hipótese é de que o eurocentrismo cria uma barreira sistêmica que inviabiliza o total sucesso das iniciativas de paz, de maneira que estas não estão devidamente preparadas para a localidade e difusão das novas disputas internacionais. Para elucidar esta hipótese, examinaremos perspectivas que procuram conjugar Educação e resolução de conflitos, utilizando fontes bibliográficas sobre o tema, bem como dados de relatórios internacionais. Nosso estudo demonstra que o pensamento eurocêntrico gera grandes restrições ao empreendimento da paz pela Educação, manifestando que as estratégias das organizações e o alcance de suas propostas se encontram circunscritos ao pensamento político ocidental.

Palavras-chave: colonialidade da paz, eurocentrismo, paz internacional, educação, República Democrática do Congo.

\section{Abstract}

This article build up an original definition of the hindrances between global and local realms in interventions of International Organizations in present conflicts. It is definition developed in a

\footnotetext{
1 Graduando em Relações Internacionais pela Universidade Federal do Rio de Janeiro - UFRJ. Email: nycolas.csilva@gmail.com.
} 
singular concept, named peace coloniality (colonialidade da paz): the process by which eurocentrism undermines the outcome of global peace efforts. It is a concept that, throught the Achille Mbembe necropolitics (necropolítica), seeks to extend níbal Quijano's understandings on Eurocentrism to the way international agencies deal with contemporary armed conflicts. Focusing on United Nations, the purpose is to analyze the efforts of conflict overcoming in present-day world, especially in the "new wars" landmark, in order to understand what structural factors make these measures not fully reach their goals. Our hypothesis is that Eurocentrism creates a systemic barrier that precludes the completeness of global efforts, as not fully prepared for the rootness and diffusion of the new international clashes. To elucidate this hypothesis, we will examine perspectives that seek to combine Education and conflict resolution, using bibliographic sources on the subject, as well as data from international reports. Our study shows that Eurocentric thinking generates great constraints to the peace enterprise through Education, stating that the strategies of the organizations and the scope of their proposals are confined to Western political thought.

Keywords: peace coloniality, eurocentrism, international peace, education, Democratic Republic of the Congo.

\section{Introdução}

A superação da violência no mundo é uma missão árdua e tradicional das Relações Internacionais. Seu principal fórum de ação está em Organizações Internacionais (OIs) que buscam prioritariamente a manutenção da paz e segurança internacionais, como a Organização das Nações Unidas (ONU). Embora "paz" seja um conceito em debate, sua premissa apresentada no preâmbulo da Carta da ONU é "preservar as gerações vindouras do flagelo da guerra" (ONU, Carta das Nações Unidas, 1945). Logo, podemos considerar que promover a paz, no marco da ONU, significa afastar a violência da guerra em todos os povos. Dentre as estratégias que perseguem este objetivo, está a Educação considerada internacionalmente um impulso indispensável à promoção da paz em abrangência universal (WINTERSTEINER, 2016, p. 124).

Mesmo assim, esta paz é ainda um objetivo distante. Na contemporaneidade, o que acompanhamos é a ampliação das guerras, que se espraiam no âmbito doméstico. Desde 1990, aproximadamente 95\% dos conflitos armados ocorrem, não entre Estados, mas dentro deles (HEYWOOD, 2013, p. 413). As chamadas novas guerras (new wars) (KALDOR, 1998), desafiam a segurança internacional, pois seus atos de violência não se restringem aos 
combatentes do Estado. São os diversos grupos de populações civis, intensamente fragmentados no interior dos países, que se apresentam tanto como agressores quanto como vítimas. Neste cenário, a ONU empreende mecanismos de intervenção, como as missões de paz, que tentam atender, neste complexo quadro doméstico, à preservação universal da vida. Entretanto, a procura da paz por tais meios, não se estabelece sem discordâncias. As operações da ONU são matéria de diversas críticas nos estudos internacionais, seja questionando sua eficiência ou reais intenções (DUFFIELD; DONINI, 2014). Tais críticas são bastante válidas, pois muitos conflitos de hoje se perpetuam sem ganharem a atenção dos atores globais. Vivemos em um mundo de guerras esquecidas: longos embates em países como República Democrática do Congo (RDC), Colômbia e Malásia que não contam com o devido acompanhamento político e midiático internacionais ${ }^{2}$.

O presente trabalho trata destas temáticas a partir dos seguintes questionamentos: quais fatores estruturais explicam os bloqueios das OIs, especialmente da ONU, ao lidar com os conflitos atuais? Por que ferramentas de pacificação como a Educação não são capazes de atingir todo potencial creditado a elas? Nossa hipótese é de que o caráter colonial do poder, padronizado pelo eurocentrismo, restringe a atuação internacional frente aos conflitos contemporâneos. Esta restrição é manifesta na resposta das OIs à diferença entre seus objetivos e a realidade no solo.

Argumentamos tais ideias em um conceito próprio, denominado "colonialidade da paz": o caráter colonial do poder expresso na busca das OIs pela paz. Este conceito parte de um diálogo entre a "colonialidade do poder", de Aníbal Quijano, e a "necropolítica" de Achille Mbembe. Iniciaremos nossa abordagem articulando pontos destas duas concepções que constroem as bases da colonialidade da paz. Após delinear nosso conceito, demonstraremos sua aplicabilidade na Educação como estratégia de paz, procurando elucidar como, desde sua elaboração teórica, esta estratégia é limitada pela colonialidade. Para concluir, construiremos uma analogia que sintetiza a abordagem do trabalho e alguns de seus efeitos práticos.

\section{Construção do Conceito: colonialidade do poder e necropolítica na atuação das organizações internacionais}

As "novas guerras" são um fenômeno essencialmente da globalização. Segundo Kaldor (2012, p. 15), é neste contexto de intensificação das interconexões globais que se consolidam as novas formas de conflito. Para tratarmos, então, das novas guerras pela ideia da colonialidade

\footnotetext{
${ }^{2}$ Mais em: <https://www.irinnews.org/in-depth/forgotten-conflicts>
} 
do poder, precisamos partir do entendimento de seu precursor, Aníbal Quijano, sobre a globalização. Para o autor, diferente de Kaldor, globalização é a padronização do poder em torno da Europa. Ela "é, em primeiro lugar, a culminação de um processo que começou com a constituição da América e do capitalismo colonial/moderno e eurocêntrico como um novo padrão de poder mundial" (QUIJANO, 2005, p. 117). Portanto, para este trabalho, a globalização indica o impulso à centralização do poder em torno do modelo político e econômico europeu que atinge seu estágio último. E é desta centralização que, para Quijano (2005), desponta a colonialidade do poder.

Partindo, então, das concepções de Quijano, a globalização, fenômeno onde as novas guerras se estabelecem, é definida pela formação de uma hegemonia eurocentrada. Esta formação se fundamenta na época da colonização europeia, mas sobrevive para além desta, implicando em um "elemento de colonialidade no padrão de poder hoje hegemônico" (Quijano, 2005, p. 117). Aqui está o ponto de partida da colonialidade da paz: acreditamos que este padrão hegemônico se estende para como as Organizações Internacionais intervém nas chamadas novas guerras. Cabe-nos, portanto, destrinchar os pontos da definição deste padrão de poder que colaboram para nosso trabalho. Desenvolveremos, portanto, não um retrato da colonialidade do poder, mas um diálogo com este conceito na perspectiva de como ele corrobora a colonialidade da paz.

Em primeiro lugar, destacamos a ideia de raça que, para Quijano (2005?), é um dos principais eixos do modelo de poder global. A classificação dos diversos povos em identidades raciais foi a principal ferramenta de dominação da Europa sobre a América. Novas identidades foram criadas - como negro, mestiço ou índio - e outras redefinidas - como europeu, português e espanhol - para corresponder não a posições geográficas, mas, a posições de poder.Assim se constitui, em primeiro lugar, a América Latina: não por seu próprio espaço e tempo, mas como projeção da conquista europeia, onde cada identidade racial corresponde a um papel na hierarquia social, sendo a Europa posta superiormente em relação a outros povos (QUIJANO, 2005, pp. 117-118).

Com a expansão da colonização, a Europa se posiciona, gradativamente, no centro do capitalismo mundial, e, portanto, ampliam-se essas relações de superioridade e inferioridade oriundas da estratificação racial: "depois da América e da Europa, foram estabelecidas África, Ásia e eventualmente Oceania" (QUIJANO, 2005, p. 121, tradução própria). A raça, destarte, consolida-se como critério básico de classificação da população a nível mundial. Ela naturaliza a hierarquia social e, consequentemente, a posição central do poder europeu. 
Assim se consolida uma progressão mundial da categorização pela raça. Este modelo de categorização tem "origem e caráter colonial, mas provou ser mais duradouro e estável que o colonialismo" (QUIJANO, 2005, p. 117). Portanto, não apenas a colonização europeia, mas os aspectos mais cruciais do poder no mundo têm características coloniais, pois são permeados pela classificação racial dos povos, elemento basilar da colonização. Estas características definem, portanto, a colonialidade do poder.

Na obra de Quijano (2005), podemos identificar a colonização da cultura como um dos traços principais desta colonialidade a nível global. Colonizar, aqui, significa reprimir o que é produzido pelos dominados, ou seja, as técnicas, subjetividades, sentidos e símbolos dos povos conquistados na colonização, e forçá-los a aprender parte da construção material e simbólica dos colonizadores, mas apenas a parte que serve à dominação dos últimos sobre os primeiros. No avanço deste processo, instaura-se um olhar eurocêntrico para todo o curso da humanidade: "os europeus ocidentais imaginaram ser a culminação de uma trajetória civilizatória" (QUIJANO, 2005, p. 122). O ponto culminante nesta trajetória é aquilo considerado avançado ou, mais propriamente, moderno. Neste sentido, o conceito de modernidade, para além de simples demarcação historiográfica, ganha numa versão eurocêntrica: a "ideia do estado de natureza como ponto de partida do curso civilizatório cuja culminação é a civilização europeia ou ocidental." (QUIJANO, 2005, p. 127).

Nesta imagem do estado de natureza reside a justificativa científica para a crença na inferioridade de certos grupos humanos, como os negros ou índios. Isto, pois o estado de natureza seria o espaço da não racionalidade, e, desde Descartes, a razão é estabelecida com a própria definição de humanidade, a característica humana por excelência. A base desta lógica está na divisão corpo e alma perpetrada pelo Cristianismo. Assim como se valoriza a alma em detrimento do corpo, enaltece-se a razão em detrimento da natureza: o corpo, por definição, é incapaz de pensar, e tudo que se conhece dele provém da razão, assim, a natureza é apenas um objeto da racionalidade. Tal “objetificação do 'corpo' como 'natureza'” (QUIJANO, 2005, p. 129) foi essencial para teorizar a raça e sua utilidade para o poder em perspectiva universal. Os povos não europeus foram considerados mais próximos da natureza que os brancos europeus, e, consequentemente, passíveis de serem dominados como simples objetos da racionalidade europeia.

Em outras palavras, a modernidade eurocêntrica é a criação de uma humanidade em curso evolucional linear que impulsiona o dualismo entre povos atrasados - cuja imagem principal é o estado de natureza - e modernos - cuja imagem principal é a racionalidade. Com 
a colonização das culturas, toda diversidade significa um descompasso na unilateralidade da história e, assim, um empecilho para que culturas atrasadas se tornem modernas. Por isso, as identidades precisam ser exauridas para completarem homogeneamente seu progresso histórico. O componente eurocêntrico se refere, para Quijano (2005), à elaboração intelectual da modernidade, onde se consolidam uma perspectiva e um modo de produção de conhecimento próprios. Em outras palavras, cria-se uma racionalidade específica, ou seja, uma visão de mundo que impulsiona a colonialidade presente na modernidade, chamada eurocentrismo. Em Quijano (2005), eurocentrismo se refere à perspectiva e ao modo de produção de conhecimento desenvolvidos pela hegemonia europeia que se sobrepõem às demais formas de conhecer. Em suas palavras:

\begin{abstract}
Eurocentrismo é, aqui, o nome de uma perspectiva de conhecimento cuja elaboração sistemática começou na Europa Ocidental antes de mediados do século XVII, ainda que algumas de suas raízes são sem dúvida mais velhas, ou mesmo antigas, e que nos séculos seguintes se tornou mundialmente hegemônica percorrendo o mesmo fluxo do domínio da Europa burguesa [...] não se refere a todos os modos de conhecer de todos os europeus e em todas as épocas, mas a uma específica racionalidade ou perspectiva de conhecimento que se torna mundialmente hegemônica colonizando e sobrepondo-se a todas as demais, prévias ou diferentes, e a seus respectivos saberes concretos, tanto na Europa como no resto do mundo. (QUIJANO, 2005, p. 16)
\end{abstract}

Entende-se, portanto, que o padrão de poder atual tem um caráter colonial desenvolvido mundialmente pela modernidade calcada no eurocentrismo. A perspectiva eurocêntrica não é exclusiva do continente europeu, mas uma visão "mundialmente hegemônica". Isto significa que é com o recorte eurocêntrico da modernidade que a colonialidade extrapola as relações coloniais e passa a representar uma visão sobre toda a humanidade e sua história, isto é, tornase universal. É possível, então, considerar que toda relação de poder é capaz de reproduzir uma perspectiva eurocêntrica e, assim, desenvolver um caráter colonial.

Voltando à construção do conceito de colonialidade da paz, partimos do princípio de que as novas guerras estão inseridas no mesmo padrão de poder mundial caracterizado por Quijano (2005). Este padrão é, em sua racionalidade, eurocêntrico, no sentido de colonizar culturas dentro e fora da Europa, e baseado na categorização social através da raça que, por sua vez, tem "origem e caráter colonial”. Observando que este caráter colonial é generalizado pela modernidade eurocêntrica, consideramos que ele pode se manifestar em qualquer exercício eurocêntrico do poder. Sendo assim, entender que as OIs, visando promover a paz, manifestam esta colonialidade, significa afirmar que: (i) elas, vislumbrando a superação dos conflitos, 
exercem algum tipo de poder e (ii) que este exercício é eurocêntrico. A partir de agora, iremos destrinchar estas duas afirmações através da necropolítica de Achille Mbembe.

A contribuição primeira de Mbembe para este trabalho está em sua compreensão ampla sobre o poder. No conceito de necropolítica, ter soberania significa "exercer controle sobre a mortalidade e definir a vida como a implantação e manifestação de poder” (MBEMBE, 2003, p. 123). Embora trate especificamente da ideia de soberania, este conceito considera que no exercício do poder em geral - sua implantação e manifestação - existe um componente de decisão sobre a vida e a morte. A soberania seria a capacidade máxima de fazer valer esta decisão, nas palavras de Mbembe, “o direito de matar” (MBEMBE, 2003, p. 128). Mas, onde se busca controlar quem vive e quem morre já existe expressão de poder. Resta-nos, então, entender se existe esta expressão na esfera das OIs. Para tal, focaremos na ONU, visto que sua missão é, essencialmente, a preservação da paz e que, para tal, empreende uma série de intervenções em conflitos.

Nas Nações Unidas, a vida é compreendida essencialmente pelo parâmetro dos Direitos Humanos. Isto fica claro no preâmbulo da Carta de São Francisco, onde a preservação da vida humana está diretamente atrelada à afirmação dos direitos fundamentais do homem:

\begin{abstract}
Nós, os povos das Nações Unidas, resolvidos a preservar as gerações vindouras do flagelo da guerra,que por duas vezes, no espaço da nossa vida, trouxe sofrimentos indizíveis à humanidade, e a reafirmar a fé nos direitos fundamentais do homem, na dignidade e no valor do ser humano, na igualdade de direito dos homens e das mulheres, assim como das nações grandes e pequenas [...] E para tais fins, praticar a tolerância e viver em paz, uns com os outros, como bons vizinhos, e unir as nossas forças para manter a paz e a segurança internacionais (ONU, 1945 - Grifo próprio).
\end{abstract}

Para que se preservem as nações da guerra, ou seja, para que não haja conflito, é necessário reconhecer direitos inerentes a toda vida humana. Estes direitos são traduzidos na Declaração Universal dos Direitos Humanos (1948), documento pensado para ser um "ideal comum a atingir por todos os povos e todas as nações" (ONU, 1948). Nota-se, portanto, que uma das concepções centrais dos Direitos Humanos e, consequentemente, das formas de se manter a paz de OIs que neles se fundamentam é o universalismo: a ideia de que ninguém pode ser excluído dos direitos e das formas de garanti-los (LANGLOIS, 2009). Portanto, organizações como as Nações Unidas trabalham com a paz na perspectiva da universalidade do direito à vida, buscando preservá-la integralmente. Sendo assim, nenhuma forma não natural de morte pode ser aceita. As OIs promotoras de paz procuram controlar a morte - eliminando- 
a em todas as suas formas violentas - e definir a vida - protegendo-a integralmente -, o que, partindo da necropolítica, significa exercer poder.

Reiterando a primeira afirmação - as OIs voltadas para a paz exercem poder precisamos observar se este poder é, em alguma medida, eurocêntrico. Vimos que o eurocentrismo é, sobretudo, um pensamento relacional: manifesta-se na interação entre culturas diferentes, estabelecendo uma como primitiva e outra como avançada, uma da natureza e a outra racional. Neste sentido, toda visão eurocêntrica reside em alguma relação de poder. No trabalho de paz de OIs como a ONU, a dinâmica relacional se dá, sobretudo, entre o organismo internacional e a realidade doméstica, ou seja, as condições do país em conflito. Neste último, a conjuntura das "novas guerras" indica conflitos cada vez mais complexos. Isto é corroborado na compreensão de Mbembe (2003), no que o autor chama de "guerras à época da globalização". Os conflitos são marcados pela dispersão da soberania, manifesta na realidade social interna aos Estados. É um momento de mobilidade global onde:

\footnotetext{
Uma de suas principais características é que as operações militares e o exercício do direito de matar já não constituem o único monopólio dos Estados, e o "exército regular" já não é o único meio de executar essas funções. A afirmação de uma autoridade suprema em um determinado espaço político não se dá facilmente. Em vez disso, emerge um mosaico de direitos de governar incompletos e sobrepostos, disfarçados e emaranhados, nos quais sobejam diferentes instâncias jurídicas de facto geograficamente entrelaçadas, e nas quais abundam fidelidades plurais, suseranias assimétricas e enclaves. (MBEMBE, 2003, p. 139).
}

Nestes moldes, compreendemos que a globalização culmina tanto a hegemonia do padrão de poder eurocêntrico, como demonstra Quijano (2005), quanto à heterogeneidade política no interior dos Estados, como aponta Mbembe (2003). Este cenário põe em choque duas formas contrastantes de necropolítica: a busca internacional por uma paz universal e a fragmentação das forças no solo reivindicando o direito de matar. Tal afirmação não significa, contudo, que estes são cenários uniformes, pois, assim como existem poderes globais ligadas à guerra, há dinâmicas locais de paz, mesmo nas sociedades em conflito (MAC GINTY, 2014). O que pretendemos demonstrar é que as OIs empreender um olhar homogêneo para realidades políticas altamente fracionadas. Ao buscarem a integralidade da vida humana, as OIs deparamse com "milícias urbanas, exércitos privados, exércitos de senhores regionais, segurança privada e exércitos de Estado", proclamando "o direito de exercer violência ou matar" (MBEMBE, 2003, p. 139).

Esta ausência de uma autoridade unificada pelo Estado é altamente contrastante com o pensamento político moderno. Segundo, Mbembe (2003) tal pensamento está calcado no 
privilégio da razão, em dicotomia com a paixão, partindo da noção de que o indivíduo deve ser racional. O Estado é entendido como a estruturação deste dever ser para o ambiente político, ou seja, “o exercício da razão na esfera pública” (MBEMBE, 2003, p. 124, tradução própria). Assim, a autoridade estatal não é mero corpo político, mas a personificação de um princípio moral, um modelo da racionalidade. Desta forma, concebe-se a noção de humanidade: só há vida humana onde há Estado, pois apenas o Estado manifesta a presença da razão.

Estes aspectos estão ligados com a colonialidade do poder desenvolvida pelo eurocentrismo. É a construção de uma visão política fundamentada no elemento chave da modernidade eurocêntrica, a razão. Não por acaso, Mbembe (2003) afirma que uso da raça pelo Ocidente como instrumento de classificação da espécie humana, foi responsável por “imaginar a desumanidade de povos estrangeiros" (MBEMBE, 2003, p. 128). Da mesma forma, imaginase a desumanidade daqueles espaços carentes da autoridade central do Estado. É justamente nestes espaços que as OIs ligadas à paz buscam exercer seu poder. Nestes casos, partindo de um pensamento eurocêntrico, a ONU seria capaz de planificar a difusão local, esvaziando a existência dos que escapam ao padrão da racionalidade, de modo que a paz se transforme num caminho finalmente universal. Em outras palavras, colonizar as culturas: homogeneizar a realidade plural para alinhar a trajetória humana.

É possível observar este processo em algumas das intervenções realizadas pela ONU em Estados africanos. As missões de paz das Nações Unidas na Somália em 1992 e 1993 (UNOSOM I e II, respectivamente) são conhecidas pela incapacidade de atingir os objetivos da ONU no país. Mesmo que com alguns sucessos, falharam em reconhecer a real situação do conflito e dialogar com as forças políticas locais. Assim, a insistência em modelos ocidentais de resolução de conflitos, como conferências diplomáticas, distantes da conjuntura sociopolítica do país, aparece como um dos principais pontos de fracasso da missão (PHILIPP, 2005, p. 550-553). A mesma disparidade entre a complexidade local e os padrões de ação da ONU pode ser observada nos entraves ao desarmamento da Operação de Paz na Libéria, a UNMIL (PAES, 2005) e no prolongamento dos conflitos em Serra Leoa (FILHO, 2012).

São casos de malogro na reconciliação entre as partes combatentes, mas exitosos na organização da burocracia estatal - eleições, reconstrução policial e auxílio à infraestrutura do governo. Vê-se, portanto que os pormenores da cultura local, principalmente no quesito político, são substituídos pela consideração de um único quesito: o Estado. A Operação de Paz das Nações Unidas na República Democrática do Congo (MONUSCO) é um exemplo emblemático desta questão. Em The Trouble with the Congo: Local Violence and the Failure 
of International Peacebuilding, Séverine Autesserre (2010) mostra como os agentes envolvidos na intervenção seguem um padrão duro, insensível às dinâmicas locais de violência e às necessidades específicas da população. Ao entrevistar agentes no solo, ela destaca as seguintes declarações:

\begin{abstract}
Os interventores estrangeiros de diferentes níveis têm a tendência de chegar com a sua bagagem, sua metodologia; às vezes eles chamam isso de 'kit de ferramentas'. Um diplomata com base em Kinshasa similarmente observou que a maioria dos oficiais da ONU usa as mesmas estratégias, escreve os mesmos relatórios e organiza a vida de modo semelhante, independente do lugar do mundo em que estejam. A maioria nem mesmo tenta contextualizar suas ações. 'Não mudaria nada para eles se, no meio da noite, você os transportasse [do Congo] para o Afeganistão' (AUTESSERRE, 2010, p. 84, tradução própria).
\end{abstract}

Este padrão está altamente ligado ao pensamento político eurocêntrico. Autesserre (2010) fala em um Leviatã perdido (the missing Leviathan), referindo-se à tendência dos interventores enxergarem violência descentralizada, isto é, não controlada pelo Estado, como um sinônimo do estado de natureza hobbesiano. Em diversas narrativas registradas pela autora, a concepção de Hobbes é utilizada por interventores para descrever o conflito congolês (AUTESSERRE, 2010, p. 69). Portanto, no ambiente local onde a autoridade central não se estabelece, as outras formas de poder são simplesmente enviesadas como uma violência permanente e incorrigível. Isto leva a visão dos interventores de que local é sinônimo de criminal (local means criminal), ou seja, de que os atos de violência descentralizada nas localidades congolesas são meros crimes, inerentes à pobreza na região, e não precisam do processo de pacificação. Como resultado, as ações da ONU se voltam para a organização do Estado pelas eleições e se afastam cada vez mais das mortes que acontecem no solo (AUTESSERRE, 2010, p. 72, 103-114).

Assim, podemos afirmar que o eurocentrismo, em especial sua versão da modernidade, incide sobre a forma de poder das OIs promotoras de paz. Existe um caráter colonial em seus esforços que diz respeito, principalmente, ao arquétipo duro do Estado que esvazia a relevância de outras possibilidades de dinâmica política. Deste modo, como bem exemplifica o caso congolês, o as estratégias de pacificação ficam fortemente limitadas. Com estas afirmações podemos, afinal, delinear o conceito de colonialidade da paz. 


\section{Colonialidade da paz: efeitos no pacifismo educacional}

Podemos definir colonalidade da paz como a forma pela qual algumas OIs em seus esforços de paz, ao intervirem nos conflitos da era global, esvaziam e homogeneízam as realidades domésticas em prol do caráter colonial do poder presente nos modelos de pensar eurocêntricos e, assim, restringem o alcance de suas metas. Resumidamente: o modo com que as bases coloniais do eurocentrismo ameaçam as estratégias internacionais de paz.

A intervenção internacional nas novas guerras (KALDOR, 2012), ou "guerras à época da globalização", contrasta dois exercícios de poder distintos: universalidade, pelo lado das OIs, e heterogeneidade, pelo lado doméstico. Sem a centralidade do Estado na totalidade dos territórios em guerra, ausenta-se o princípio racional de humanidade estabelecido pela ótica moderna. A necropolítica das OIs - a proteção de toda vida humana contra toda morte violenta - é, então, obstaculizada: como preservar a vida humana onde não se encontra o princípio da humanidade?

O eurocentrismo aparece, então, como força estrutural que orienta o exercício de poder das OIs e serve à superação deste obstáculo. Como vimos, ele se expande pela modernidade eurocêntrica, cuja compreensão política valoriza o modelo estatal ocidental em detrimento de qualquer outro cenário. Mais que um modelo, a autoridade do Estado nesta estrutura funciona como ponto de inflexão entre sociedades tidas como racionais e avançadas e outras vistas como atrasadas, que ainda se encontram no estado de natureza ou próximo dele. Pelo princípio ocidental da razão como atributo máximo do humano, isto significa a divisão entre sociedades com e sem humanidade. Assim, a preservação da vida só será possível onde está preservado o Estado, pois ali está preservada a razão.

Ademais, muitas das sociedades em conflito contemporâneas são ex-colônias onde, a difusão de "máquinas de guerra" é fruto, justamente, da incapacidade do processo colonial em construir bases econômicas e políticas sólidas em seus domínios (MBEMBE, 2003, p. 140). Nas ex-colônias, reside um pensamento sobre violência eurocêntrico, que deriva da visão do Estado como bastião público da razão, pois, o mundo colonial foi, na expansão europeia, o exemplo por excelência do mundo sem Estados, ou seja, a terra onde não havia vida a ser preservada. Desta forma, a brutalidade nas colônias foi altamente banalizada, devido ao fato de que seus nativos eram considerados elementos sem vida, sem humanidade, meros selvagens. A violência nestes contextos se tornou não apenas justificável, mas natural: “é impossível firmar a paz com eles” (MBEMBE, 2003, p. 133, tradução própria). 
Por isso, ao olhar para territórios politicamente plurais e pulverizados, as OIs não encontram a humanidade que se propõem a preservar. Sua atuação passa a depender, portanto do restabelecimento da autoridade estatal, ou de ações nas porções do território em que esta autoridade ainda se impõe. De qualquer modo, esvaziam os países de suas complexidades sociopolíticas e reduzem-nas unicamente à presença ou não do Estado. Considerando que apenas por este arquétipo se entende que a paz é possível, o resultado direto deste processo é a limitação das estratégias de paz. Principalmente porque, como vimos, a premissa central do modo de atuação dos organismos internacionais é a universalidade. Por sua necropolítica, não deveria haver nenhum limite ao alcance da preservação da vida.

Dentre os variados mecanismos de paz, a Educação é um dos que melhor reflete a premissa da universalidade. Desde a Declaração Universal dos Direitos Humanos, entende-se que o sistema de Estados deve garantir - especialmente às crianças - um ensino universal, isto é, um direito provido a todos gratuita e igualmente. Diz a declaração:

1. Todo ser humano tem direito à instrução. A instrução será gratuita, pelo menos nos graus elementares e fundamentais. A instrução elementar será obrigatória. A instrução técnico-profissional será acessível a todos, bem como a instrução superior, está baseada no mérito.

2. A instrução será orientada no sentido do pleno desenvolvimento da personalidade humana e do fortalecimento do respeito pelos direitos do ser humano e pelas liberdades fundamentais. A instrução promoverá a compreensão, a tolerância e a amizade entre todas as nações e grupos raciais ou religiosos e coadjuvará as atividades das Nações Unidas em prol da manutenção da paz. (ONU, , 1948, grifo próprio).

Este entendimento é reiterado por outros documentos como o Pacto Internacional para Direitos Econômicos, Sociais e Culturais e a Convenção sobre os Direitos das Crianças. Como aponta Wintersteiner (2016, p. 110-111), nestes tratados, entende-se que a Educação, ao menos o nível básico, além de universal, é capaz de promover valores específicos defendidos pelas Nações Unidas, como a tolerância, a amizade e o respeito. Não por acaso, após afirmar a promoção destes valores, a Declaração versa que "[a instrução] coadjuvará as atividades das Nações Unidas em prol da manutenção da paz”. O mesmo sequenciamento de ideias aparece no artigo 13 do Pacto Internacional dos Direitos Econômicos, Sociais e Culturais (1966). Isto indica a expectativa internacional de que o ensino possa promover, sem barreiras, valores entendidos como pacíficos.

Todo este esforço global se torna ainda mais abrangente com a introdução dos Objetivos de Desenvolvimento Sustentável pela Agenda 2030 (2016). Neste, a universalidade da educação vai além do ensino básico, visto que os Estados se comprometem em garantir 
igualdade de acesso em todos os níveis educacionais, da alfabetização à universidade (arts. 4.3 e 4.6). Não se pretende necessariamente a gratuidade em todos estes níveis, mas se almejam medidas de viabilização econômica para países em situação de desvantagem (art. 4.b). Provida universalmente, a Educação deve ocorrer em "ambientes de aprendizado seguros e nãoviolentos" na qual os alunos possam promover uma "cultura de paz e não violência, cidadania global, e valorização da diversidade cultural" (arts. 4.7 e 4.a).

Contudo, estes objetivos estão ainda distantes da realidade. Os países, mesmo os chamados desenvolvidos, continuam com hiatos significativos em seus sistemas educacionais (WINTERSTEINER, 2016, p. 111). Neste sentido, Unesco e Unicef (2015) entenderam que educação para todos era uma "promessa quebrada", especialmente para as crianças vulneráveis à violência: cerca de 50\% das crianças fora da escola em 2015 estavam em países em conflito armado. Acreditamos ser possível explicar estas barreiras pela colonialidade da paz. Demonstraremos como, desde a base teórica, a superação de conflitos pela Educação não apresenta um pensamento universalizante. Este exame, contudo, não tem a pretensão de esgotar a literatura no assunto, mas sim, salientar perspectivas que mais representam o pensamento internacional no tema. Destarte, selecionamos como ponto de partida dois trabalhos que relacionam as abordagens teóricas com seus impactos na prática. Entretanto, ambos os escritos defendem as vantagens de um ponto de vista sobre os outros. Para fazer apontamentos mais autônomos, construiremos uma estruturação própria das ideias a partir do que desenvolveram os autores.

\section{Perspectivas de educação e paz}

Bush e Saltarelli (2000) organizam as teorias sobre pedagogia e pacificação em duas categorias: (i) educação para paz (peace education) e (ii) educação para o peacebuilding (peacebuilding education), colocando-se ao lado da última. Já Gill e Niens (2014) especificam quatro perspectivas pedagógicas: (i) educação para cidadania (citizenship education), (ii) educação de valores (values education), (iii) educação sobre a história (history education) e (iv) educação crítica (critical education), sendo favoráveis a esta última. Acreditamos que é possível aproximar algumas destas visões a partir dos aspectos destacados por sua ótica de educação. As perspectivas que abordam valores e cidadania podem ser enquadradas, principalmente, no conceito mais amplo de peace education. Já a history education, em nossa visão, caracteriza-se mais como tema possível dentro das diversas abordagens e menos como 
um modo específico de pensar a educação ${ }^{3}$. Sobre a educação crítica, concordamos com Gill e Niens (ano) de que ela configura uma perspectiva particular. Utilizaremos, portanto, estas três categorias - educação para paz, educação crítica e educação para o peacebuilding. Ressalta-se que estas ideias não se restringem ao debate acadêmico, mas servem de subsídio para as agências da ONU em suas ações (UNICEF et al., 2011).

\title{
Educação para paz
}

Embora não apresente uma definição específica do termo, Bush e Saltarelli (2000) dedicam um tópico de seu livro a distinguir peace e peacebuilding education, iniciando com a seguinte afirmação:

\begin{abstract}
Em qualquer discussão sobre educação para a construção da paz, existe uma clara necessidade de ir além das abordagens baseadas predominantemente no estudo acadêmico e no treinamento. Primeiro, o estudo acadêmico é muitas vezes removido do mundo real, da aplicação e da consideração prática de implicações ou impactos. Em segundo lugar, a ideia de treinamento parece estar baseada em soluções geradas externamente e impostas, que falham em reconhecer a possibilidade de que capacidades de construção da paz cultural e específicas possam existir, e serem mais apropriadas e sustentáveis. (BUSH; SALTARELLI, 2000, p. 26, tradução própria).
\end{abstract}

Deste trecho, compreendemos que a educação para a paz abarca concepções de educação menos preocupadas com o impacto local, que priorizam estratégias de treinamento, e não processos de longo prazo, onde valores pacíficos são impostos de cima para baixo. Esta definição destaca uma crença comum no assunto, de que a passividade é fruto do ensinamento de certos valores a crianças e jovens. Duas das abordagens apresentadas por Gill e Niens fazem uso dessa crença: (i) a educação de valores e (ii) a educação para cidadania.

A educação de valores é uma pedagogia voltada para a promoção de virtudes que se acredita serem comumente aceitas entre culturas e sociedades. Já a educação para cidadania é tomada de um caráter mais prático, baseada em atividades extracurriculares e na participação do aluno no ambiente escolar, mas, da mesma forma, busca imputar valores específicos, como equidade, justiça e participação democrática, a fim de gerar uma convivência social pacífica. Como apontam os autores, ambas as perspectivas são limitadas por sua pouca adaptabilidade às complexidades locais. Os valores a ser ensinados dificilmente superam as dinâmicas culturais das sociedades onde estão mergulhadas as escolas, ou mesmo da própria estrutura escolar,

\footnotetext{
${ }^{3}$ Existem estratégias específicas para lidar com a narrativa histórica de grupos em conflito. Nosso ponto, contudo, é que tais estratégias podem ser aplicadas por todas as perspectivas apresentadas se incorporam o estudo da História.
} 
funcionando muito mais como fator de reprodução de uma cultura hegemônica do que de transformação das relações de poder e violência (GILL; NIENS, 2014, p. 16-18).

É importante salientar, no entanto, que há uma vertente da educação de valores consciente desta problemática e que busca superá-la. É o caso de Leenders e Veugelers (2006) que propõem a adoção da democracia crítica como abordagem pedagógica para a promoção de certas virtudes. Nela, os estudantes teriam a oportunidade de contribuir com a comunidade através de sua própria visão, e não de concepções pré-moldadas, unindo, assim, a transmissão de valores pacíficos com sua comunicação participativa em sociedade (LEENDERS; VEUGELERS, 2006, p. 27). Portanto, esta perspectiva busca desenvolver nos alunos uma postura democratizante, que vá além da participação escolar, e que esteja fundamentada em suas relações interpessoais. Nesta concepção, a democracia deve se somar aos debates da Teoria Crítica, o que nos leva a discutir parte de suas contribuições no tópico seguinte. Aqui, cabe resgatar o argumento de Gill e Niens (2014): as forças culturais subordinam as iniciativas pedagógicas. Deste modo, elementos como a democracia podem ser enviesados por relações de significado e poder ao invés de absorverem concepções diversas.

\section{Educação crítica}

As abordagens seguintes tentam superar os limites da educação para a paz. Neste sentido, destaca-se a educação crítica que, com base nos estudos da Escola de Frankfurt, busca desafiar as relações desiguais de poder ao discutir o próprio processo de aprendizagem, ou seja, indagando o que, como e porque aprendemos e ensinamos. A relação entre as estruturas de poder e o espraiar da violência nas sociedades aproximou a educação crítica das discussões sobre a paz internacional, desenvolvendo o que podemos chamar de educação crítica para a paz (critical peace education) (Gill e Niens, 2014, p. 19).

Temos, portanto, uma abordagem que, a princípio, preocupa-se menos com a imputação de valores pacíficos e apura o olhar para a transformação dos padrões institucionais de desigualdade e conflito através da educação. Entretanto, os críticos a esta perspectiva apresentam uma oposição relevante: implicitamente, a educação crítica assume que certos valores são universais, ou seja, que é possível encontrar um ponto de convergência social alheio às diversas tensões, interesses e diferenças de valores (GILL; NIENS, 2014, p. 19). Tal tendência fica clara já no texto de Gill e Niens (2014). Nele, defendem que o diálogo no ensino nos conduziria a uma jornada emancipatória para além das diversas barreiras sociais, colocando-nos frente a frente como humanos. Assim, a educação crítica acaba se apoiando nesta noção abstrata de humanidade, deslocada das diversas condições socioculturais. A humanidade 
é definida por valores pré-concebidos, ou seja, entendimentos que prescindem da visão de cada cultura sobre o que é ser humano. Niens, em outro artigo, admite que as "pedagogias críticas podem ser restringidas por barreiras estruturais e sociais" (REILLY; NIENS, 2014, p. 72).

Compreendendo estes desafios, devemos refletir sobre a ideia de democracia crítica defendida por Leenders e Veugelers (2006). Ao contrário de uma pedagogia em prol da noção de humano, os autores conjugam a Teoria Crítica com a educação para valores de modo a considerar as diferentes visões de mundo não como superáveis, mas como ponto de partida do diálogo. Assim, a reflexão crítica é promovida sem que se almejem valores universais, mas motivando a participação de cada aluno com sua individualidade e criatividade (LEENDERS; VEUGELERS, 2006, p. 26). Devemos avaliar, entretanto, até que ponto a democracia pode ser considerada um elemento neutro, gerador do debate plural e respeitoso às diversidades. Além do conceito de democracia estar sujeito a diversas variações culturais, os autores demonstram que o equilíbrio entre a transformação e a reprodução de valores depende intensamente da postura de cada educador. Não se espera que o professor seja totalmente neutro, mas ele não deve impor princípios e valores, possibilitando que sejam respeitadas as diferentes visões de mundo. Neste sentido, o fator de ajuste entre internacional e doméstico deixa de ser, especialmente, a cultura local para pesar sobre a figura do educador. Este parece ser um elemento forte da abordagem crítica como um todo, já que a proposta de Reilly e Niens (2014) para enfrentar os desafios da aplicação pedagógica também recai sobre engajamento do profissional de educação (REILLY; NIENS, 2014, p. 73).

Nota-se, portanto, que a vertente de democracia crítica busca maior adaptabilidade às realidades locais. Entretanto, a instrumentalização desta iniciativa através da democracia, embora possível, é bastante limitada. Assim, a próxima perspectiva busca uma nova forma de prezar pelos territórios em conflito.

\section{Educação para o peacebuilding}

Segundo Bush e Saltarelli (2000, p. 27):

A educação para a construção da paz - como o peacebuilding em si - seria um processo de baixo para cima dirigido por comunidades devastadas pela guerra, baseado em suas experiências e capacidades. [...] E incluiria o ensino de técnicas de gerenciamento de conflitos e habilidades de leitura e o cultivo dos valores da tolerância cultural e da não-violência.

Portanto, as alternativas de peacebuilding education são aquelas que destacam o processo de enraizamento local da Educação e o protagonismo das próprias comunidades na 
construção da paz. Aqui, os elementos pacíficos a serem imputados ganham menos ênfase. O principal objetivo é entrar em contato com as realidades locais e dar voz às comunidades atingidas pela violência.

Para que este tipo de aproximação seja possível, os agentes externos devem adequar sua postura perante os grupos locais. Eles apontam que a velocidade da superação da violência dependerá das diferentes formas de relação entre os diferentes grupos, ou seja, é a complexidade local que define o caminhar das iniciativas. E esta deve ser não só uma simples ideia, mas um ponto de partida concreto das estratégias de paz:

\begin{abstract}
Quando se trata de iniciativas educacionais que pretendem ter um impacto benéfico nas relações intergrupais, um ponto de partida útil é o reconhecimento de que uma medida nunca serve para todos. Em alguns casos, uma medida não serve para ninguém. Consequentemente, a eficácia de uma iniciativa educacional aumenta na medida em que é flexível e responsiva. (BUSH; SALTARELLI, 2000, p. 25).
\end{abstract}

Após examinar as três abordagens, percebe-se que a educação para o peacebuilding é a que mais se afasta dos efeitos da colonialidade da paz. A relevância e o cuidado com os contextos específicos se apresentam como condições fundamentais contra a criação de normas pedagógicas de cima para baixo, que acabam por padronizar as soluções possíveis em realidades difusas. Ao abdicarem destas prerrogativas, as outras perspectivas se tornam vulneráveis às barreiras da homogeneização eurocêntrica.

Mesmo assim, a pedagogia defendida por Bush e Saltarelli (2000) ainda impõe significativas restrições ao alcance dos atributos educativos. Embora não especifique um único campo de ação para as propostas, sua obra faz diversas referências às chamadas "sociedades devastadas pela guerra" (war-torn societes) como palco mais imediato da abordagem (BUSH; SALTARELLI, 2000). Uma leitura possível, portanto, é que sua ideia principal é colaborar com locais já devastados por conflitos e que precisam ser reconstruídos - e não transformados - pela ação educativa ${ }^{4}$. Territórios ainda em guerra estariam menos propícios à ação pedagógica. Observa-se, deste modo, que a possibilidade de uma educação internacional fora do eixo colonial encontra um importante limitador no modo de se enxergar a extensão de um conflito. A classificação dos níveis de violência define, em grande parte, o alcance das estratégias de paz.

Perspectivas de paz e terminologias da guerra

\footnotetext{
${ }^{4}$ O termo "reconstrução" (reconstruction) é utilizado no texto para descrever a área de atuação da UNICEF Innocenti Research Centre (IRC), instituição financiadora do estudo.
} 
Paul Lederach (1995) argumenta que os agentes e estudiosos engajados na superação de contendas desenvolveram no campo três nomenclaturas sobre a forma de lidar com tais lutas: (i) resolução de conflitos (conflict resolution), (ii) Gestão de conflitos (conflict management) e (iii) transformação de conflitos (conflict transformation). Cada um destes termos guarda um pensamento sobre até que ponto é possível superar um conflito.

O conceito de resolução é tradicional na área e continua dominante. Foi promovido por estudos sobre como um conflito se inicia e termina. A partir desta reflexão, buscou-se desenvolver estratégias e habilidades para lidar com os resultados voláteis e destrutivos de um embate. Este foco nos resultados acabou por valorizar a busca pela restauração social, em detrimento de um entendimento mais profundo sobre as razões que levam ao confronto. Deste modo, o conflito passa a ser visto como um mal a ser combatido por ações objetivas, enquanto alcances estruturais e de longo prazo perdem o foco (LEDERACH, 1995, p. 16).

Nos anos 1980 e 1990, começa a aparecer a terminologia conflict management. Este conceito, bastante ocidental, entende que conflitos ocorrerão não como rompimento social, mas como fenômeno natural das relações humanas. Entretanto, isto não é visto como algo catastrófico, pois, nesta visão, os confrontos seguem determinados padrões. Assim, o conflito é concebido como um acontecimento ordinário, cujo andamento pode ser compreendido e, por conseguinte, controlado (LEDERACH, 1995, p. 16-17).

Nascido nos anos 1990 e desenvolvido até os dias atuais, o conceito de conflict transformation é defendido pelo próprio Lederach como uma forma mais completa e dinâmica de se tratar a questão. Neste, as estratégias não visam eliminar ou controlar as causas de conflito, mas canalizar sua força destrutiva para ações construtivas. O nome transformação se baseia na ideia de que o conflito é um fenômeno potencialmente transformador das relações sociais. Deste modo, acredita-se ser possível partir das diversas pressões geradas em nível micro para impulsionar mudanças substanciais a nível sistêmico (LEDERACH, 1995, p. 18).

Nesta última terminologia, as medidas pacificadoras são tomadas de um potencial bastante completo. Aqui, acredita-se que ferramentas como a educação podem transpor inteiramente as diversas situações de violência para um cenário estrutural de paz. Boa parte das perspectivas sobre educação, contudo, se prendem a certas habilidades pedagógicas como fontes únicas de paz e deixam de considerar uma mudança social mais completa, complexa e sistêmica. Aqui, o pensamento colonial se expressa profundamente: a paz é vista como sinônimo da reprodução de valores gerais, ou seja, como homogeneização das culturas a partir de uma pretensa universalidade moral (GILL; NIENS, 2014, p. 10-11). A ideia de que é 
necessário imputar certos preceitos nas sociedades em conflito, indica a crença de que tais comunidades estão moralmente vazias. Expressasse-se o processo eurocêntrico onde toda cultura precisa se exaurir em prol daquilo que é imposto como único.

Já a educação crítica tem objetivos bem próximos da completa transformação das estruturas de violência. Contudo, esta missão fica circunscrita aos parâmetros da ideia de emancipação, e o conflito precisa ser gerido dentro destas condições específicas, como na terminologia da gestão de conflitos. Boaventura de Souza Santos $(1991 ; 2008)$ aponta como esta pode ser uma situação de controle - e não de mudança - da sociedade. Para o autor, o positivismo científico reduziu boa parte do esforço emancipa tório à racionalidade ocidental, o que acabou por colonizá-lo e instrumentalizá-lo para a regulação da sociedade (SANTOS, 1991, p. 137). Ao se apoiar em um humanismo de valores pré-concebidos, acreditamos que a educação crítica trabalhe com a noção colonial de uma emancipação arraigada ao princípio da racionalidade que, como já vimos, causa a exclusão de toda cultural não ocidental.

Desta digressão sobre as perspectivas de educação e paz, podemos concluir que um primeiro impacto da colonialidade se dá sobre as estratégias pacificadoras em si. Com o exemplo da educação, é possível notar que, mesmo ideias que tentam conduzir uma superação total das estruturas de violência, estão limitadas pela visão distante sobre os territórios em que se posicionam. O exemplo teórico máximo estaria na educação para o peacebuilding. Aproximando-se da terminologia da transformação, pretende estar adaptado aos contextos em guerra, mas ainda limita sua abordagem pelo avanço do conflito: quanto mais latente, menos possível de transformar o conflito pela educação. Com a colonialidade da paz, compreendemos o porquê desta noção: as novas guerras, quando em curso, refletem a dispersão dos poderes em detrimento do comando do Estatal. Nestas condições, próximas do estado de natureza das colônias, a paz é vista como impossível.

Por agora, compreendemos que a colonialidade da paz entrava o desenvolvimento de esforços holísticos, ou seja, que pensem a superação de toda violência para todos os integrantes de uma sociedade. Assim, temos a situação do Quadro 1. Se considerarmos que a capacidade educativa corresponde ao nível de expectativa quanto aos resultados alcançáveis - ou seja, o quanto a educação pode fazer - e o papel da educação corresponde à formulação teórica de como ela pode atuar - ou seja, o que a educação pode fazer - temos a noção de que uma ação holística de paz pela educação não chega a ser considerada, nem teoricamente, possível. 


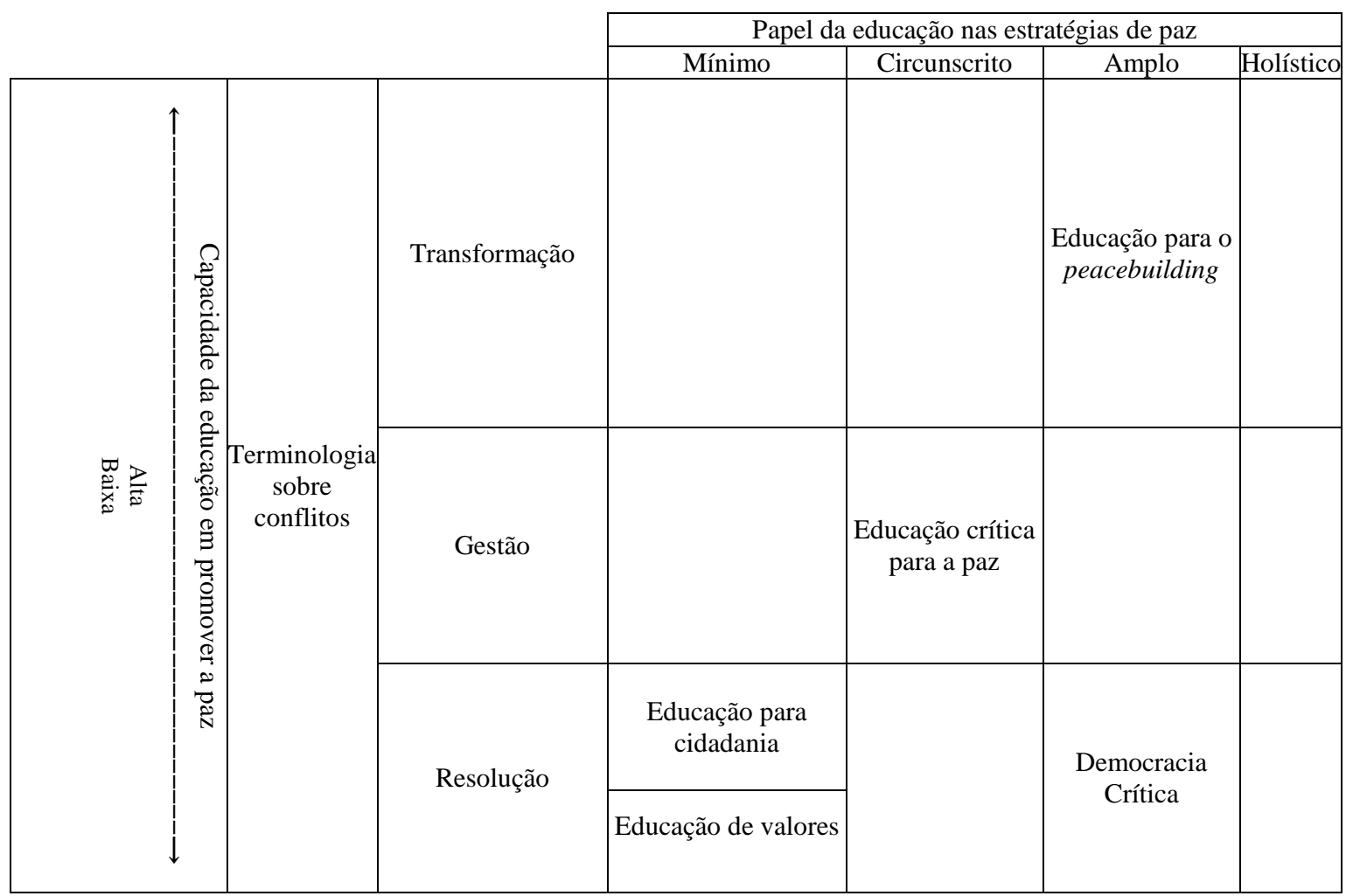

Quadro 1: atributos da educação para as perspectivas de educação e paz

Fonte: Elaboração própria

\section{Conclusão}

Para sintetizar o conceito de colonialidade da paz, podemos construir a seguinte analogia: imaginemos os esforços de paz como missões de exploração em território desconhecido. Neste cenário, um conjunto de exploradores sai do seu ambiente para adentrar um espaço externo e tentar alcançar os objetivos da missão. No processo, podemos supor também que não partem do vácuo, mas utilizam os parâmetros disponíveis em seu ambiente para tentar garantir o sucesso da empreitada. Contudo, em um lugar inexplorado, as condições locais, por vezes, são diferentes do que foi previamente avaliado. Nestas circunstâncias, os exploradores têm a possibilidade de estudar apenas as porções do território que condizem com os parâmetros estabelecidos, ou absorver as exigências da nova realidade e reconfigurar seus objetivos e estratégias.

De modo semelhante, as OIs, intervindo em conflitos, saem de seu ambiente para outro - da esfera internacional para a esfera doméstica. Neste processo, formulam os resultados de paz esperados a partir dos parâmetros internacionais disponíveis. Com o conceito de 
necropolítica, vimos que, em geral, a expectativa das OIs, ou a chave do seu exercício de poder, é preservar universalmente a vida. Contudo, a globalização gera novas condições no território doméstico, novas guerras, que, por sua alta fragmentação, dificultam a universalidade desta proposta. Por sua vez, os parâmetros disponíveis na estrutura internacional estão hegemonicamente marcados pelo caráter colonial do poder, pois a visão eurocêntrica vicia toda a estrutura. Portanto, voltando à analogia, as OIs comumente escolhem restringir sua atuação, agindo pelo parâmetro eurocêntrico. Este define que só há vida humana onde há controle do Estado. Assim, é satisfeita a universalidade do direito à vida como premissa, mas não como ação. Onde a vida é reconhecida ela é universalmente preservada, onde não é, perdura a violência. A humanização de todos em nome da paz universal é substituída pela desumanização de muitos em nome da universalidade da paz.

Além de trazer o caso de algumas intervenções, procuramos aplicar este conceito a uma estratégia de paz específica: a Educação. Vimos que, embora seja atribuída ao aprendizado a prerrogativa de difundir paz em todas as realidades do mundo, ele se concentra na realidade de apenas alguns. Isto porque, o esvaziamento cultural causado pelo eurocentrismo limita o fôlego das abordagens pedagógicas em compreender e dialogar com as culturas locais. Algumas, como a peace education, nem mesmo buscam este contato. Outras, mesmo que se pretendam a isso, continuam com uma visão enviesada das culturas locais, o que restringe o potencial holístico da pacificação pelo ensino. Na educação crítica a ideia de emancipação guarda em si o princípio ocidental da racionalidade, apagando as realidades não-ocidentais, o que é mantido pela via da democracia crítica, pois o próprio conceito de democracia não se adapta a cada contexto. Já a peacebuilding education, embora mais distante da colonialidade, ainda a manifesta na maneira como olha para as sociedades em conflito e padroniza suas chances de pacificação de acordo com o nível de avanço da guerra.

Portanto, ainda que se atribua à Educação, ou a outras estratégias, um caráter pacífico universal, o caráter colonial do poder se sobressai: predominam as visões pasteurizadas e enviesadas sobre a realidade de cada país. O caminho para uma paz verdadeiramente universal passa, portanto, pela maior valorização de cada cultura em detrimento dos padrões do eurocentrismo. Um caminho árduo, sem dúvida, porém não mais difícil que a missão de levar a paz a todos os povos do mundo.

\section{Referências Bibliográficas}


AUTESSERRE, S. The Trouble with the Congo: Local Violence and the Failure of International Peacebuilding. New York: Cambridge University Press, 2010.

BEKERMAN, Z.; ZEMBYLAS, M. Teaching Contested Narratives: Identity, memory and reconciliation in peace education and beyond. New York: Cambridge University Press, 2011.

BUSH, K. D.; SALTARELLI, D. The Two Faces of Education in Ethnic Conflict: Towards a peacebuilding education for children. Florence: UNICEF Innocenti Research Centre, 2000.

DUFFIELD, M.; DONINI, A. Global Governance and the New Wars: The Merging of Development and Security. London \& New York: Zed Books, 2001.

FILHO, J. M. V. Promover a Paz ou Prolongar Conflitos: a dualidade das missões de paz da ONU em Serra Leoa. Coimbra: Universidade de Coimbra, 2012.

GILL, S.; NIENS, U. Education as Humanisation: a theoretical review on the role of dialogic pedagogy in peacebuilding education. Compare: Journal of Comparative and International Education. v. 44, p. 10-31, 2014.

HEYWOOD, A. Politics. $4^{\circ}$ ed. New York: Red Globe Press, 2013.

KALDOR, M. New and Old Wars: organized violence in a global era. 3. ed. Cambridge: Polity, 2012.

LANGLOIS, A. J. Human Rights Universalism. In: HAYDEN, Patrick. The Ashgate Research Companion to Ethics and International Relations. Ashgate Publishing, 2009, p.201-214.

LEDERACH, J. P. Preparing for Peace: Conflict Transformation Across Cultures. New York: Syracuse University Press, 1995.

LEENDERS, H.; VEUGELERS, W. Different Perspectives on Values and Citizenship Education. In: Global Values Education - Teaching Democracy and Peace. New York: James Nicholas Publishers, v. 21, 2006. p. 5-20.

MAC GINTY, R. Everyday Peace: Bottom-up and local agency in conflict-affected societies. Security Dialogue, v. 45, 2014, p. 548-564.

MBEMBE, A. Necropolítica. Public Culture, 2013, p. 11-40.

MITCHELL, C. R. The Structure of International Conflict. London: Palgrave Macmillan UK, 1989.

ORGANIZAÇÃO DAS NAÇÕES UNIDAS. Carta das Nações Unidas. [24 de Outubro de 1945]. Disponivel em: <https://nacoesunidas.org/carta/>. Acesso em: 21 out. 2018.

_. Declaração Universal dos Direitos Humanos, v. 13, 1948. 
_. Transformando Nosso Mundo: A Agenda 2030 para o Desenvolvimento Sustentável, [Setembro de 2015]. Disponível em: < https://nacoesunidas.org/pos2015/>

PAES, W.-C. The Challenges of Disarmament, Demobilization and Reintegration in Liberia. International Peacekeeping, v. 12, 2005, p. 253-261.

PHILIPP, C. E. Somalia: very special case. Berlin: Max Planck Yearbook of United Nations Law Online, v. 9, 2005, p. 517-554.

QUIJANO, A. Colonialidade do Poder, Eurocentrismo e América Latina. Buenos Aires: Consejo Latinoamericano de Ciencias Sociales (CLACSO), 2005. Disponivel em: <http://bibliotecavirtual. clacso. org. ar/ar/libros/lander/pt>. Acesso em: 21 out. 2018.

REILLY, J.; NIENS, U. Global Citizenship as Education for Peacebuilding in a Divided Society: Structural and contextual constraints on the development of critical dialogic discourse in schools. Compare: Journal of Comparative and International Education, v. 44, 2014, p. 53-76.

SANTOS, B. D. S. Subjectividade, Cidadania e Emancipação. Revista Crítica de Ciências Sociais, Coimbra, v. 45, 1991, p. 135-191.

SANTOS, B. D. S. Do Pós-Moderno ao Pós-Colonial. E para além de um e de outro. Paraná: Travessias, v. 6/7, p. 15-36, 2008.

UNESCO; UNICEF. Fixing the broken promise of education for all: Findings from the Global Initiative on Out-of-School Children, 2015. Disponível em: <http://allinschool.org/wpcontent/uploads/2015/01/OOSC-EXECUTIVE-Summary-report-EN.pdf>. Acesso em: 21 out. 2018 .

UNICEF; et. al. The Role of Education in Peacebuilding: Literature review, 2011. Disponível em:

<https://www.unicef.org/infobycountry/files/EEPCT_Peacebuilding_LiteratureReview.pdf > Acesso em: 21 out. 2018.

_. Global Initiative for Out-Of-School: West and Central Africa Report, 2014. Disponível em: 〈http://unesdoc.unesco.org/images/0022/002280/228081e.pdf>. Acesso em: 21 out. 2018. WINTERSTEINER, W. International Strategies for Building a Culture of Peace Through Access to Good Education. In: KURY, Helmut. Women and Children as Victims and Offenders: Background, Prevention, Reintegration. Berlin: Springer, 2016, p. 107-138. 